ONLINE MUTATION REPORT

\title{
Genomic duplication in Dyggve Melchior Clausen syndrome, a novel mutation mechanism in an autosomal recessive disorder
}

\author{
E Kinning, C Tufarelli, W S Winship, M A Aldred, R C Trembath
}

J Med Genet 2005;42:e70 (http://www.jmedgenet.com/cgi/content/full/42/12/e70). doi: 10.1136/jmg.2005.033829

Background: Dyggve Melchior Clausen syndrome (DMC) is a severe autosomal recessive skeletal dysplasia associated with mental retardation. Direct sequencing of genomic DNA has identified causative mutations in the gene Dymeclin (chromosome 18q12-21), with the majority predicting the generation of a truncated protein product.

Objective: To carry out molecular genetic studies in three DMC kindreds.

Results: Two novel nonsense mutations and two complex genomic duplication events resulting in exon repetition were identified.

Conclusions: Exon dosage assessment or mRNA analysis, in addition to direct genomic DNA sequencing, should be employed in the investigation of DMC affected individuals. Genomic duplication may be the causative mutation mechanism in other autosomal recessive disorders.

$\mathrm{T}$ he skeletal dysplasias are a heterogeneous group of at least 200 distinct clinical disorders affecting approximately 1 in 4000 individuals in European populations. ${ }^{1}$ Dyggve Melchior Clausen syndrome (DMC, OMIM 223800), an autosomal recessive spondylo-epimetaphyseal dysplasia, is characterised by short trunk dwarfism, microcephaly, a coarse facial appearance, and mental retardation. ${ }^{2}$ Radiographs show multiple abnormalities including vertebral platyspondyly, lacy iliac wings, laterally displaced irregularly ossified femoral heads, and a hypoplastic odontoid. ${ }^{3}$ Aspects of the DMC phenotype mirror the clinical features seen in the mucopolysaccharidosis known as Morquio's disease; hence chondrocyte dysfunction was postulated to be a result of abnormal metabolite storage. ${ }^{2}$ However, biochemical studies have been inconsistent, such that pathogenesis of DMC remains unclear. Autozygosity mapping led to the localisation of a DMC disease gene to chromosome 18q12-21, with no evidence of locus heterogeneity. ${ }^{45} \mathrm{~A}$ few mutations were detected in a gene encoding the predicted transcript termed FLJ 20071. ${ }^{67}$ The DMC gene spans approximately $400 \mathrm{~kb}$ and is composed of at least 17 exons. ${ }^{67}$ Dymeclin, the protein product of the DMC gene, is widely expressed and several splicing isoforms have been predicted (Aceview, NCBI), and differentially sized transcripts seen on northern blot. ${ }^{6}$ The longest open reading frame encodes a putative transmembrane protein of 669 amino acids $(75 \mathrm{kDa})$, but to date the exact nature and function of the protein is unknown. The analysis of naturally occurring mutations is instrumental in gaining functional insights and more generally in understanding the molecular mechanisms causing human genetic disease.

For a better understanding of the allelic architecture of DMC mutations, we undertook a molecular screen of affected subjects from three kindreds. We now report the identification and characterisation of four novel disease alleles including complex genomic rearrangements which, when expressed, result in exon duplication or repetition. Recent studies have suggested that regions of the human genome may be subject to regional duplication/deletion on a large scale, which we show may lead to gene disruption and subsequent disease. ${ }^{8}$

\section{METHODS}

Genotyping and DMC gene mutation analysis

Four subjects from three independently ascertained kindreds were investigated. Multicentre research ethics approval was given for the study (South East MREC, London). Pedigrees are illustrated in fig 1. Genomic DNA was extracted from peripheral blood leucocytes according to standard protocols. Microsatellite markers extending over a $3.1 \mathrm{Mb}$ distance surrounding the DMC locus (fig 1 and supplementary tables 1 and $2^{*}$ ) were amplified in multiplex polymerase chain reactions (PCR) and the products separated by electrophoresis on an ABI 377 DNA fragment analyser. Alleles were scored manually using Genescan v3.1 and Genotyper v2.0 software (Applied Biosystems, Foster City, California, USA).

All 16 coding exons of the DMC gene, together with the exon-intron boundaries, were amplified as previously described. ${ }^{6}$ Products were purified and sequenced on an ABI 377 automatic sequencer using the fluorescent dideoxyterminator method. Primer sequences are available as supplementary material.

Reverse transcriptase PCR and fluorescent dosage PCR RNA was extracted either from peripheral blood collected into Paxgene ${ }^{\circledR}$ collection tubes (Qiagen, Valencia, California, USA) following the manufacturer's instructions or from EBV transformed lymphocyte cell lines (subjects 7261 and 7345) using RNeasy kit (Qiagen). Complementary DNA was synthesised by priming with oligo-dT using First Strand cDNA synthesis kit (Roche Diagnostics, Lewes, UK). DMC cDNA was amplified in eight overlapping PCR products and size separated on $2 \%$ agarose gel (supplementary table 3 ). Products of an aberrant size were extracted using a Gel purification kit (Qiagen) and purified DNA sequenced as described above.

Fluorescent dosage PCR to quantify locus specific genomic DNA was carried out as a multiplex assay using the primers listed in supplementary table 4 and Qiagen multiplex PCR master mix. DMC exons 2, 14, and 15 were amplified together with ALK1 exon 2 (control), samples run on an ABI

Abbreviations: DMC, Dyggve Melchior Clausen syndrome; DQ, dosage quotient; STR, simple tandem repeat

*The supplementary tables can be viewed on the journal website (www. imedgenet.com/supplemental). 

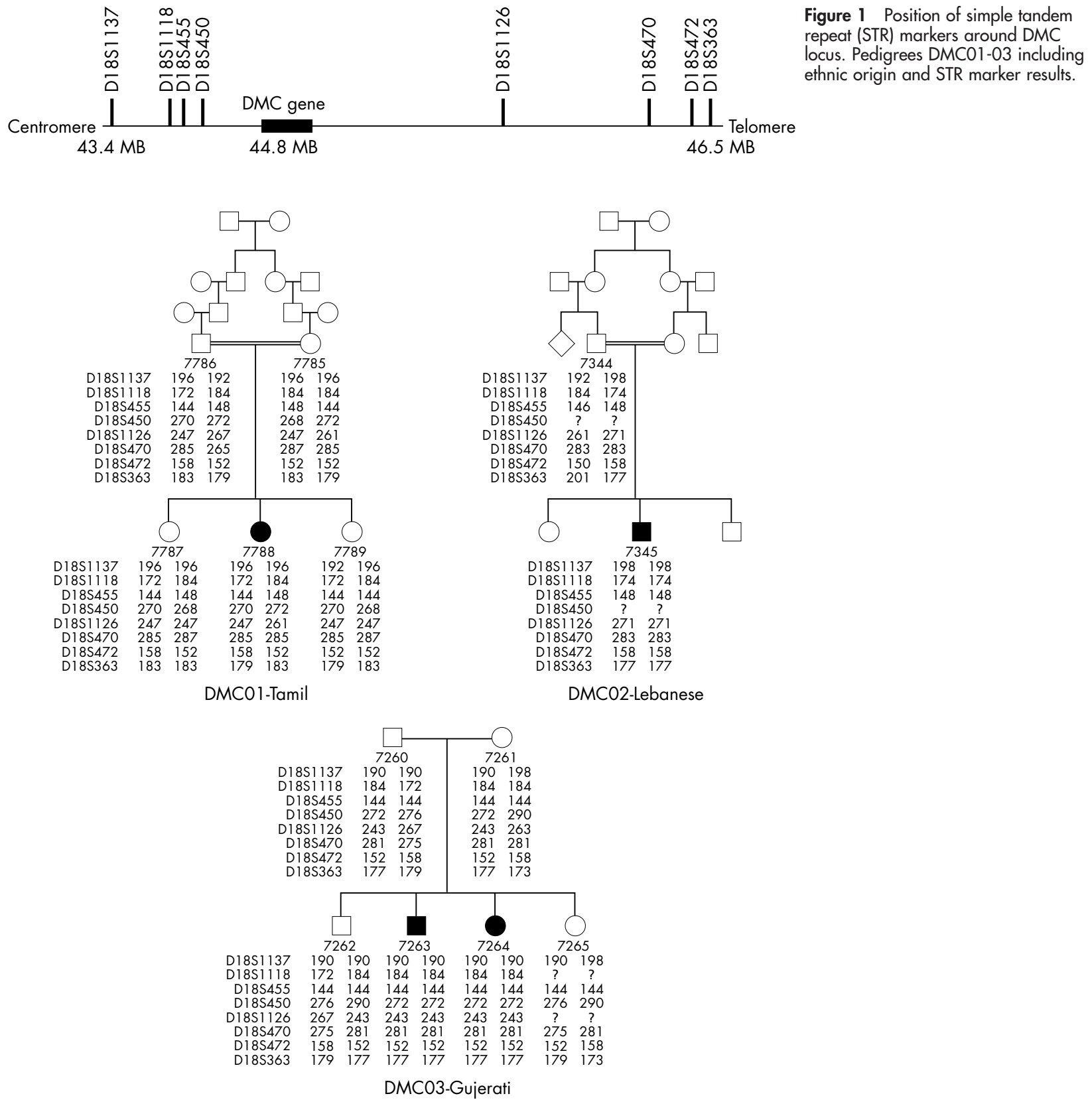

377 DNA fragment analyser, and gels analysed using the software packages Genescan v3.1 and Genotyper v2.0. Three independent experiments were done and used for comparison. The mean peak area for each exon was calculated for 10 control samples and used to compare with patient samples. Dosage quotients (DQ) were calculated for the exon of interest in relation to two other DMC exons or ALKl exon 2 using the following formula, as previously described': DQ exon a/exon $b$ $=[$ sample exon $a$ peak area $/$ sample exon $b$ peak area $] \div[-$ control exon $a$ peak area/control exon $b$ peak area].

\section{Southern blot analysis}

A total of $10 \mu \mathrm{g}$ of genomic DNA was digested with the restriction enzyme PvuII or ApaLI and separated on $0.8 \%$ agarose gel. After electrophoresis DNA was transferred to Zeta probe membrane (Biorad) by alkaline blotting according to the manufacturer's instructions. A $25 \mathrm{ng}$ sample of probe DNA was ${ }^{32} \mathrm{P}$ labelled with $15 \mu \mathrm{Ci}\left[\alpha^{32} \mathrm{P}\right] \mathrm{dCTP}$ (NEN Life Science, Boston, Massachusetts, USA) in a standard random primed reaction (Invitrogen, San Diego, California, USA). Hybridisation was undertaken at $65^{\circ} \mathrm{C}$ for 16 hours, membranes were washed twice at $65^{\circ} \mathrm{C}$ in $2 \times \mathrm{SSC} / 0.1 \%$ SDS (sodium dodecyl sulphate) for 20 minutes, then twice in $0.1 \times \mathrm{SSC} / 0.1 \%$ SDS at $65^{\circ} \mathrm{C}$ for 20 minutes. The filters were exposed to a Storage Phosphor screen for 16 hours and analysed on a Typhoon ${ }^{\circledR}$ phosphoimager using ImageQuant software (Amersham Biosciences, Amersham, UK). DMC exon 2 and exon 14 probes correspond, respectively, to 298 base pairs (bp) of DMC cDNA including all of exon 2 and $1040 \mathrm{bp}$ of DMC genomic DNA including all of exon 14, as illustrated in fig 3A.

\section{RESULTS}

\section{Identification of new mutations in the DMC gene}

In kindred DMC01, the proband (7758) was heterozygous for all informative genotypes at surrounding polymorphic markers (fig 1). Direct sequencing showed a paternally inherited $\mathrm{C} \rightarrow \mathrm{T}$ transition at nucleotide position 208 (exon 4) leading to the introduction of a premature stop codon 
A

Forward primer
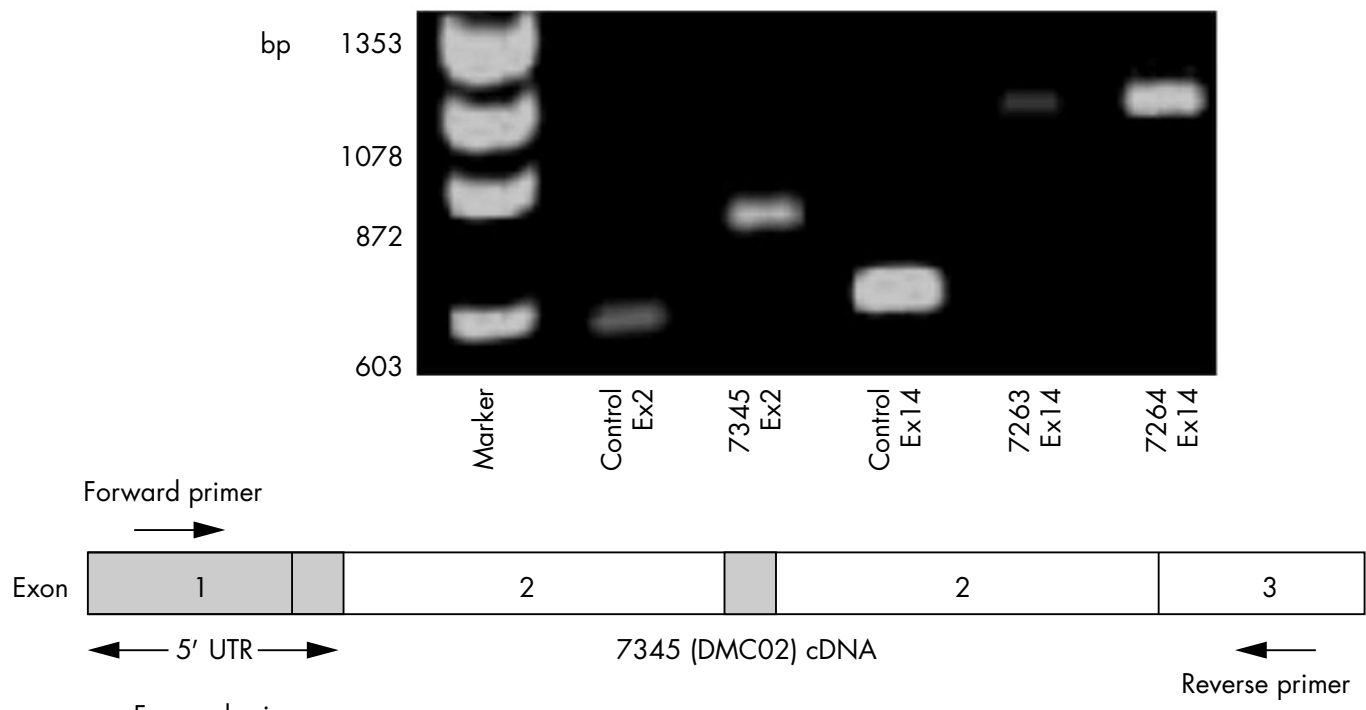

Forward primer

Reverse primer

\begin{tabular}{c|c|c|c|c|c|}
\hline Exon & 14 & 14 & 14 & 14 & 15 \\
\hline \multicolumn{7}{c|}{7263 and 7263 (DMC03) cDNA } \\
\hline
\end{tabular}

B

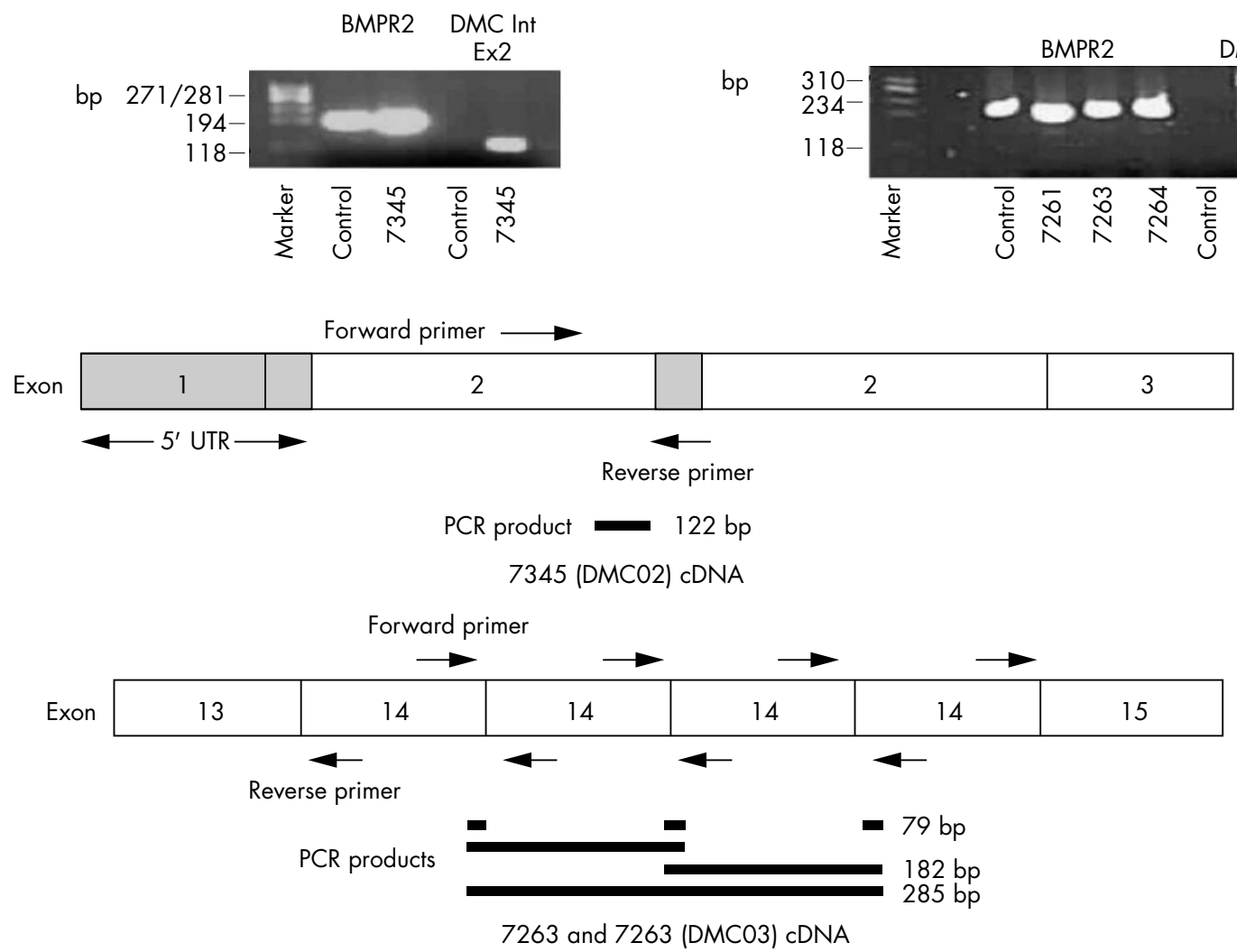

Figure 2 (A) Reverse transcriptase polymerase chain reaction (RT-PCR) gel image and schematic of cDNA amplified. Dyygre Melchior Clausen syndrome (DMC) cDNA amplified with forward primer in exon 1 (5' untranslated region) and reverse primer in exon 3 produces product of 574 base pairs (bp) in control compared with approximately 800 bp in 7345. DMC cDNA amplified with forward primer in exon 13 and reverse primer in exon 15 produces product of $594 \mathrm{bp}$ in control compared with approximately $1000 \mathrm{bp}$ in 7263 and 7264 . (B) RT-PCR gel image and schematic of aberrant subject cDNA amplified. Forward primer at the end of exon 2 and reverse primer at the beginning of exon 2 do not produce a product in control cDNA as expected. A product of $122 \mathrm{bp}$ is shown in 7345. Forward primer at the end of exon 14 and reverse primer at the beginning of exon 14 do not produce a product in control cDNA but products of 79182 and 285 bp are shown in 7261, 7263, and 7264. A BMPR2 amplicon of 191 bp is produced for all samples. 
A 298 bp cDNA probe including all of exon 2 (+ partial exon 1 and 3 sequence)

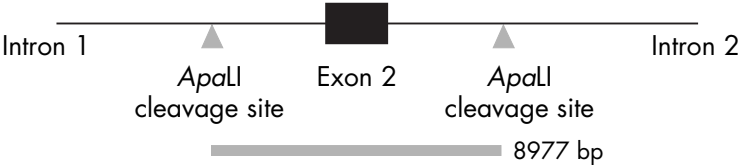

Apall cleavage sites in wild type sequence produce fragment of 8977 bp
1040 bp genomic DNA probe including all of exon 14 (+ intron 13 and 14 sequence)

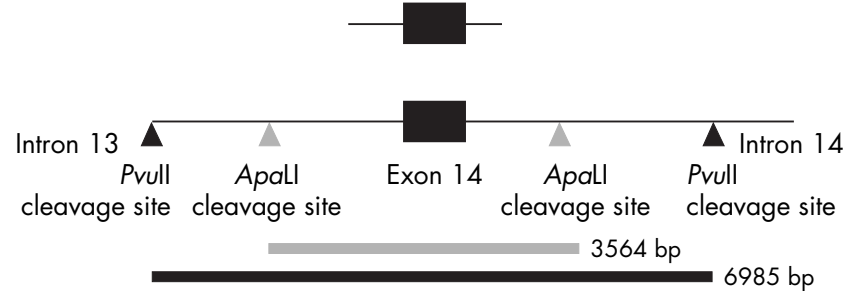

Pvull and ApaLl cleavage sites in wild type sequence produce fragments of 6985 and 3564 bp respectively

B

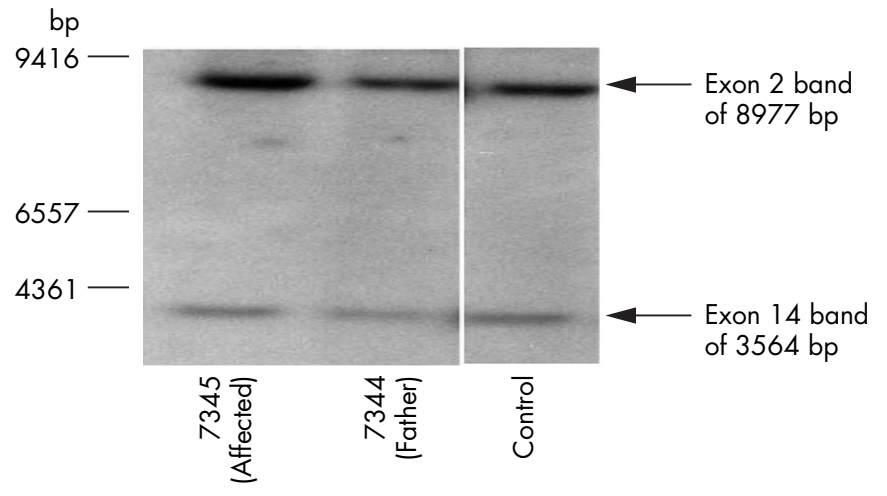

C

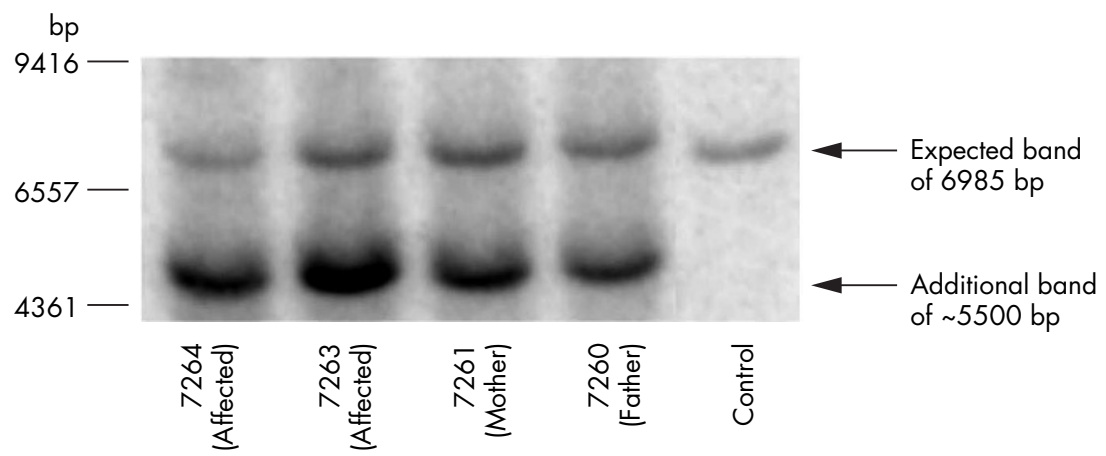

Figure 3 (A) Schematic illustrating probes used for Southern blotting, and restriction enzyme cleavage sites. Exon 2 probe comprises 298 base pairs (bp) of cDNA sequence including all of exon 2 in addition to partial exon 1 and 3 sequence. Following digestion of wild type sequence with ApaLl and probing with exon 2 probe, a fragment of 8977 bp will be produced. Exon 14 probe comprises 1040 bp of genomic DNA sequence including all of exon 14 and surrounding intronic sequence. Following digestion of wild type sequence with ApaLl or Pvull and probing with exon 14 probe, fragments of 3564 and $6985 \mathrm{bp}$, respectively, will be produced. (B) Southern blot analysis. Following digestion of genomic DNA with ApaLl and sequential probing with DMC exon 2 and exon 14 probes, fragments of the expected sizes, respectively 8977 and 3564 bp, were seen both in control samples and in DMC02 proband (7345) and father (7344). Densitometry of exon 2 to exon 14 restriction fragments showed a ratio of 2:1 in 7345, 3:2 in 7344, and 1:1 in control. (C) Southern blot analysis. Pvull digestion of genomic DNA in DMC03 subjects (7263 and 7264) and both parents (7260 and 7261) revealed a smaller aberrantly sized fragment of approximately $5500 \mathrm{bp}$ in addition to a fragment of the expected size (6985 bp).

replacing an arginine residue (R70X). The maternal chromosome harboured a mutation at nucleotide position 1363 (exon 12), also a $\mathrm{C} \rightarrow \mathrm{T}$ transition, which results in the introduction of a premature stop codon (R455X).

Homozygosity for all eight simple tandem repeat (STR) markers across the DMC locus at chromosome 18 was observed for each of the three affected subjects from kindred DMC02 (7345) and DMC03 (7263,7264). Family studies identified distinct putative disease bearing haplotypes not shared by either family (fig 1). Direct sequencing of genomic DNA in each of the affected subjects failed to reveal any deleterious sequence variants. Reverse transcriptase polymerase chain reaction (RT-PCR) analysis of lymphocyte derived DMC exon 1 to exon 3 cDNA from subject 7345 (DMC02) revealed an aberrantly sized product of approximately 800 bp compared with the $574 \mathrm{bp}$ fragment observed in control subjects. Sequencing of the gel purified product revealed a 193 nucleotide duplication encompassing all of exon 2 including the coding region ( $140 \mathrm{bp}$ ) and the $5^{\prime}$ untranslated region (53 bp) (fig $2 \mathrm{~A}$ ).

Amplification of exons 13 to 15 of DMC cDNA of probands in kindred DMC03 identified approximately $1000 \mathrm{bp}$ fragments, significantly larger than the 594 bp amplification seen in control subjects, and sequence analysis revealed tandem repeats of four copies of exon 14 (fig 2A). To confirm these findings, RT-PCR was carried out using primer pairs, each predicted to generate a product specific to the aberrant repeated cDNA sequences but not in the normal sequence (fig $2 \mathrm{~B}$ and supplementary table 3 ). Bands of the sizes expected (122 bp in 7345 and 79,182 , and 285 bp in 7263 and 7264) were seen in affected individuals and parents from 
whom RNA was available (fig 2B) and were not detected in control (normal) cDNA. Positive control RT-PCR amplification of a $191 \mathrm{bp}$ product of BMPR2 (chromosome 2q36-37) was done and revealed a product in all samples tested.

Analysis by fluorescent dosage PCR revealed DQs for DMC exon 2 compared with either DMC exons 14, 15, or ALK1 exon 6 (chromosome 12q1l-14) in individual 7345 (DMC02) of $\sim 2$ (exon 2 as the numerator). DQs for DMC exon 14 compared with either DMC exons 2, 15, or ALKl exon 6 in affected subjects 7263 and 7264 (DMC03) were $\sim 4$ (data not shown).

\section{Southern blot analysis}

Following digestion of genomic DNA with ApaLI and sequential probing with DMC exon 2 and exon 14 probes, bands of the expected sizes (8977 and 3564 bp, respectively) were seen in control samples and DMC02 proband (7345) and father (7344), as illustrated in fig 3B. A maternal DNA sample was not available. ImageQuant software analysis confirmed the ratio of exon 2 and exon 14 band density as 2:1 in 7345 (affected) and 3:2 in 7344 (father) normalised to control samples. Following digestion of high molecular weight DNA with the restriction enzyme PvuII and Southern blot analysis with a DMC exon 14 probe, a band of the expected size (6985 bp) was seen both in control samples and DMC03 affected individuals $(7263,7264)$ and parents $(7260,7261)$. However, an additional fragment of approximately 5500 bp was observed in each DMC03 family member tested, as shown in fig 3C. Analysis following digestion with ApaLI revealed restriction fragments of the expected size only.

\section{DISCUSSION}

In a screen of subjects affected with DMC we have identified four novel DMC mutations including complex genomic rearrangements that when transcribed result in exon duplication or repetition. We unexpectedly identified two nonsense mutant alleles inherited as compound heterozygote in the offspring of cousin parents (DMC01). These findings highlight a potential limitation to the method of autozygosity mapping (the method used to identify the DMC disease gene), widely adopted in gene mapping of rare recessive disorders.

Previous reports have identified 16 DMC mutations distributed among 21 kindreds (table 1 ) by direct sequencing of genomic DNA; hence gross deletions/rearrangements/ duplications would not have been identified. These disease alleles were seen to segregate with classical DMC or the allelic disorder Smith McCort dysplasia, distinguished from DMC by the absence of mental retardation. ${ }^{6710}$ Reviewing all mutations including those in this report, it is apparent that the majority (14/20 (70\%)) of DMC alleles predict the generation of a truncated protein product, some as a result of a frameshift (including by exon skipping) and subsequent premature termination codon. This supports the hypothesis that loss of dymeclin function is the likely mechanism of disease pathogenesis. While the spectrum of mutations now identified provides compelling evidence that the DMC protein product is necessary for normal chondrocyte activity, the precise function of dymeclin remains unclear. The observation of dilated rough endoplasmic reticulum and multiple vacuoles in chondrocytes of affected individuals suggests that lack of dymeclin may lead to abnormal processing or defective synthesis of cartilage proteins. ${ }^{11}$

The exon 2 duplication and exon 14 repetition predict the insertion of 22 and six amino acids, respectively, followed by a premature termination codon. It is expected that the transcript would be destroyed by nonsense mediated decay with subsequent failure to produce a protein product. The ATG initiator codon is located in exon 2; thus if translation was initiated in the second copy of exon 2 a normal transcript would be produced. However, exon 2 contains only 53 bp of untranslated sequence, which may not be sufficient to promote the use of this initiation site and hence translation may preferentially occur at the first ATG.

The existence of exon repetition of mRNA in the absence of genome duplication has been reported both in rat and human genes. $^{12}{ }^{13}$ However, fluorescent dosage analysis of PCR

Table 1 Dyygve Melchior Clausen syndrome (DMC) mutations

\begin{tabular}{|c|c|c|c|c|c|c|}
\hline Nucleotide change & DMC exon & $\begin{array}{l}\text { Amino acid } \\
\text { change }\end{array}$ & $\begin{array}{l}\text { Consequence on } \\
\text { protein }\end{array}$ & Phenotype & Ethnic origin & Reference \\
\hline $\mathbf{G} \rightarrow \mathbf{C} 34$ bp $3^{\prime}$ of exon 1 & Intron 1 & & $?$ & DMC & Portuguese & 10 \\
\hline Duplication exon 2 & Exon 2 & $\mathrm{~S} 47 \mathrm{R}+\mathrm{FS}$ & $\begin{array}{l}\text { Frameshift and } \\
\text { truncation }\end{array}$ & DMC & Lebanese & This report \\
\hline C48G & 2 & Y16X & Truncated & DMC & Dominican & 7 \\
\hline C208T & 4 & R70X & Truncated & DMC & Tamil & This report \\
\hline IVS 3 194-1G $\rightarrow A$ & $\begin{array}{l}4 \text { (5' end) splice } \\
\text { acceptor }\end{array}$ & & Skipping exon 3 & DMC & Lebanese & 10 \\
\hline G259A & 4 & E87K & Missense & SMC & Guamese & 7 \\
\hline IVS $4 \quad 288-2 A \rightarrow G$ & $\begin{array}{l}5 \text { ( } 5 \text { ' end) splice } \\
\text { acceptor }\end{array}$ & & Skipping exon 4 & DMC & Spanish & 10 \\
\hline T396A & 5 & Y132X & Truncated & DMC & Not stated & 7 \\
\hline C580T & 7 & R194X & Truncated & DMC & Tunisian & 6 \\
\hline C610T & 7 & R204X & Truncated & DMC & Morroccan & 6 \\
\hline T656G & 8 & R219X & Truncated & DMC & Morroccan & 6 \\
\hline 763delA & 8 & $\mathrm{~T} 254 \mathrm{Q}$ & $\begin{array}{l}\text { Frameshift and } \\
\text { truncation }\end{array}$ & DMC & Not stated & 7 \\
\hline IVS 7-1 T $\rightarrow$ G & $\begin{array}{l}8 \text { (5'end) splice } \\
\text { acceptor }\end{array}$ & & Skipping exon 7 & SMC & Guamese & 7 \\
\hline IVS $10 \quad 1125+1 G \rightarrow T$ & $\begin{array}{l}\left.10 \text { ( } 3^{\prime} \text { end }\right) \text { splice } \\
\text { donor }\end{array}$ & & $\begin{array}{l}\text { Skipping exon } 11 \text { (in } \\
\text { frame) }\end{array}$ & DMC & Morroccan & 6 \\
\hline $\mathrm{C} 1363 \mathrm{~T}$ & & R455X & Truncation & DMC & Tamil & This report \\
\hline IVS $11 \quad 1252-1 G \rightarrow A$ & $\begin{array}{l}\left.12 \text { ( } 5^{\prime} \text { end }\right) \text { splice } \\
\text { acceptor }\end{array}$ & & $\begin{array}{l}\text { Skipping exon } 11 \text { (in } \\
\text { frame) }\end{array}$ & DMC & Lebanese & 6 \\
\hline A1405T & 13 & N469Y & Missense & DMC & Not stated & 7 \\
\hline C1447T & 13 & Q483X & Truncated & DMC & Morroccan & 6 \\
\hline $\begin{array}{l}\text { Repetition } 4 \text { copies exon } \\
14\end{array}$ & 14 & $\mathrm{~A} 525 \mathrm{~F}+\mathrm{FS}$ & $\begin{array}{l}\text { Frameshift and } \\
\text { truncation }\end{array}$ & DMC & Gujerati & This report \\
\hline 1877delA & 17 & $\mathrm{~K} 626 \mathrm{~N}+\mathrm{FS}$ & $\begin{array}{l}\text { Frameshift and } \\
\text { extension }\end{array}$ & DMC & Morroccan & 6 \\
\hline
\end{tabular}


amplified lymphocyte derived genomic DNA provided independent confirmation of the genomic rearrangements. Southern blot analysis in subjects from kindred DMC02 did not reveal any novel restriction fragments, and a doubling of exon 2 band density in the proband (compared with exon 14 and normalised to control) suggests that the duplicated sequence includes the entire sequence between ApaLI restriction sites (fig 3, panels $\mathrm{A}$ and $\mathrm{B}$ ). In contrast, hybridisation with the DMC exon 14 probe after PvuII digestion of genomic DNA from DMC03 subjects revealed an aberrantly sized fragment of approximately $5500 \mathrm{bp}$ in addition to a fragment of the expected size (6985 bp), as illustrated in fig 3C. ApaLI digestion showed only fragments of the expected size. We interpret the above data to suggest that at least one of the external copies has been unaffected by the duplication, and hence a fragment of the expected size is produced. The exact nature of the duplication is not yet known but our results suggest the duplicated sequence is likely to start between the ApaLI and PvuII restriction sites (fig 3A).

We used BLAST analysis of the DMC intronic sequence surrounding exons 2 and 14 to search for regions of homology where non-allelic homologous recombination or replication slippage may have arisen. This revealed multiple Alu repeat sequences, including several in the region between $P v u I I$ and ApaLI cut sites surrounding exon 14 which Southern blot analysis indicated may be the site of initiation of duplication. Rearrangements arising at Alu elements have been reported in several conditions including Duchenne muscular dystrophy, and are estimated to account for $0.3 \%$ of human genetic diseases. ${ }^{14}$ Recent studies have highlighted the existence of variation in copy number of large segments of the human genome and suggested that this phenomenon may be more common than previously thought. Genomic imbalance was detected in approximately $50 \%$ of individuals tested in one study, including regions containing known genes. ${ }^{15}$ However, the sample sizes were small and using mathematical estimates based on Duchenne muscular dystrophy as a model, others have suggested that one in eight humans will have a segmental deletion and one in 50 a duplication. ${ }^{8}$ Interestingly, increased gene density has been found in duplicons, suggesting that this phenomenon may be an important mechanism underlying mutations causing many human diseases. ${ }^{16}$ It may even account for a proportion of individuals whose phenotype appears to be linked to a disease gene but in whom mutations are not identified by standard mutation screening techniques.

While we were unable to characterise exactly the real extent of genomic duplication, implicit in our observations is the assumption that the duplication events encompass sufficient intronic sequence to enable normal splicing. We are now seeking to characterise in more detail the duplicated intronic sequence in both cases, which may provide further insight into the underlying mechanism.

\section{Conclusions}

This study has identified novel mutations including complex genomic rearrangements of the DMC gene, each likely to disrupt the normal function of the protein product significantly. Genomic duplication mutations have not previously been reported in DMC and this study highlights the merit of using additional methods of mutation analysis in this severe skeletal dysplasia. Genomic duplication leading to gene disruption may be an important mechanism underlying other human genetic disorders.

\section{ACKNOWLEDGEMENTS}

We would like to thank the families who participated in this study, Shanta Patel, Nabitha Chabilal, and Dr Ashok Vellodi for assistance with patient recruitment, and Professor Christine Hall (Great Ormond Street Hospital, London) for review of radiographs. This work was funded by the Medical Research Council through a clinical training fellowship to EK.

\section{ELECTRONIC DATABASES}

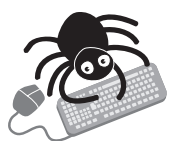

The supplementary tables can be viewed on the journal website (www.jmedgenet.com/supplemental).

\section{Authors' affiliations}

E Kinning, C Tufarelli, M A Aldred, R C Trembath, Division of Medical Genetics, Departments of Genetics and Cardiovascular Science, University of Leicester, Leicester, UK

E Kinning, R C Trembath, Leicestershire Genetics Centre, Leicester Royal Infirmary

W S Winship, Department of Paediatrics, University of Natal, South Africa

Competing interests: none declared

Correspondence to: Professor Richard Trembath, Division of Medical Genetics, Department of Genetics and Cardiovascular Science, University of Leicester, University Road, Leicester LE1 7RH, UK; richard.trembath@genetics.kcl.ac.uk

Received 8 April 2005

Revised version received 26 May 2005

Accepted for publication 30 May 2005

\section{REFERENCES}

1 Stoll C DB, Roth MP. Birth prevalence rates of skeletal dysplasias. Clin Genet 1989;35:88-92.

2 Beighton P. Dyggve-Melchior-Clausen syndrome. J Med Genet 1990;27:512-15.

3 Spranger J, Maroteaux P, Der Kaloustian VM. The Dyggve-Melchior-Clausen syndrome. Radiology 1975;114:415-21.

4 Ehtesham N, Cantor RM, King LM, Reinker K, Powell BR, Shanske A, Unger S, Rimoin DL, Cohn DH. Evidence that Smith-McCort dysplasia and DyggveMelchior-Clausen dysplasia are allelic disorders that result from mutations in a gene on chromosome 18q12. Am J Hum Genet 2002:71:947-51.

5 Thauvin-Robinet C, El Ghouzzi V, Chemaitilly W, Dagoneau N, Boute O, Viot G, Megarbane A, Sefiani A, Munnich A, Le Merrer M, Cormier-Daire V. Homozygosity mapping of a Dyggve-Melchior-Clausen syndrome gene to chromosome 18q21.1. J Med Genet 2002;39:714-17.

6 El Ghouzzi V, Dagoneau N, Kinning E, Thauvin-Robinet C, Chemaitilly W, Prost-Squarcioni C, Al Gazali L, Verloes A, Le Merrer M, Munnich A, Trembath RC, Cormier-Daire V. Mutations in a novel gene Dymeclin (FU20071) are responsible for Dyggve-Melchior-Clausen syndrome. Hum Mol Genet 2003;12:357-64.

7 Cohn DH, Ehtesham N, Krakow D, Unger S, Shanske A, Reinker K, Powell BR, Rimoin DL. Mental retardation and abnormal skeletal development (DyggveMelchior-Clausen dysplasia) due to mutations in a novel, evolutionarily conserved gene. Am J Hum Genet 2003;72:419-28.

8 Van Ommen GB. Frequency of new copy number variation in humans. Nat Genet 2004;37:333-4.

9 Yau SC BW, Mathew CG, Abbs SJ. Accurate diagnosis of carriers of deletions and duplications in Duchenne/Becker muscular dystrophy by fluorescent dosage analysis. J Med Genet 1996;33:550-9.

10 Paupe V, Gilbert T, Le Merrer M, Munnich A, Cormier-Daire V, El-Ghouzzi V. Recent advances in Dyggve-Melchior-Clausen syndrome. Mol Genet Metab 2004;83:51-9

11 Engfeldt B, Bui TH, Eklof O, Hierpe A, Reinholt FP, RitzenEM, Wikstrom B. Dyggve-Melchior-Clausen dysplasia. Morphological and biochemical findings in cartilage growth zones. Acta Paediatr Scand 1983;72:269-74.

12 Frantz SA, Thiara AS, Lodwick D, Ng LL, Eperon IC, Samani NJ. Exon repetition in mRNA. Proc Natl Acad Sci USA 1999;96:5400-5.

13 Rigatti R, Jia JH, Samani NJ, Eperon IC. Exon repetition: a major pathway for processing mRNA of some gene is allele specific. Nucleic Acids Res 2004;32:441-6.

14 Deininger PL, Batzer MA. Alu repeats and Human Disease. Mol Genet Metab 1999;67:183-93.

15 lafrate AJ, Feuk L, Rivera MN, Listewnik ML, Donahoe PK, Ying Q, Schere SW, Lee $C$. Detection of large-scale variation in the human genome. Nat Genet 2004;36:949-51.

16 Fredman D, White SJ, Potter S, Eichler EE, Den Dunnan JT, Brookes AJ. Complex SNP-related sequence variation in segmental genome duplications. Nat Genet 2004;36:861-6. 